\title{
Intrinsically conductive polymer fibers from thermoplastic trans-1,4-polyisoprene
}

\author{
Peng Han, Xiaohong Zhang, and Jinliang Qiao*
}

Sinopec Beijing Research Institute of Chemical Industry, Beijing, 100013 (P.R. China)

E-mail: qiaojl.bjhy@sinopec.com

\section{Instrumentation.}

Wide Angle X-Ray Diffraction (WAXD) experiment was carried out on the Bruker D8 DISCOVER 2D X-Ray diffractometer. The X-ray was generated using I $\mu$ S micro Focus X-Ray source incorporating a $50 \mathrm{~W}$ sealed-tube X-ray generator with $\mathrm{Cu}$ target. The wavelength is $0.1542 \mathrm{~nm}$. The power of the generator used for measurement was $45 \mathrm{kV}$ and $0.9 \mathrm{~mA}$. The X-ray intensities were recorded on a VÅNTEC-500 2D detector system with a pixel size of $68 \times 68 \mu \mathrm{m}^{2}$. The distance from the sample to detector was $82.8 \mathrm{~mm}$. The spot size of the beam was $0.5 \mathrm{~mm}$. The exposure time was 2 min. Small Angle X-ray Scattering (SAXS) was conducted using Bruker NANOSTAR SAXS instrument. The I $\mu$ S-type generator was operated at $40 \mathrm{kV}$ and $650 \mu \mathrm{A} . \mathrm{Cu}$ radiation with wavelength of $0.1542 \mathrm{~nm}$ was used for the experiment. The scattering data were collected by Hi Star area detector, which has the resolution of $1024 \times 1024$ pixels and $100 \mu \mathrm{m}$ in pixel size. The detector-to-sample distance was $1053 \mathrm{~mm}$. 
Figure S1. SAXS images of TPI fibers. (a) Fibers with diameter of $0.7 \mathrm{~mm}$ without drawn. (b) Fibers with diameter of $0.7 \mathrm{~mm}$ drawn from diameter of $1.2 \mathrm{~mm}$.
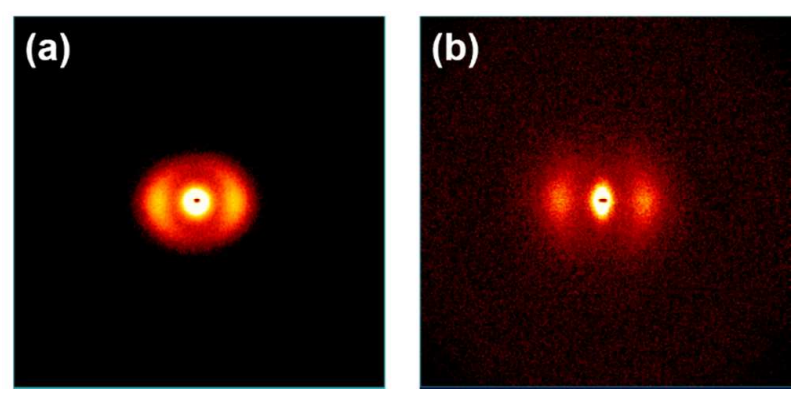

Figure S2. WAXD images of iodine-doped TPI fibers. (a) Doped fibers with diameter of $0.7 \mathrm{~mm}$ without drawn. (b) Doped fibers with diameter of $0.7 \mathrm{~mm}$ drawn from diameter of $1.2 \mathrm{~mm}$.
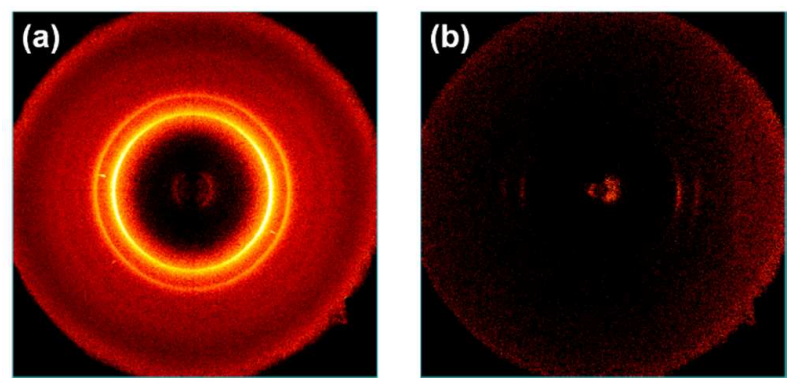